\title{
La reforma de la conscripción en el Perú en el tránsito del siglo XIX al XX. La aplicación de la Ley del Servicio Militar Obligatorio de 1898*
}

\section{David Víctor Velásquez SiLVA}

Afiliado institucionalmente a la Universidad Nacional Mayor de San Marcos (Lima/Perú), director del Fondo Editorial y Librería de la Universidad Nacional Mayor de San Marcos. Correo electrónico: dvelasquezs@ unmsm.edu.pe. El autor es Magíster y licenciado en Historia por la Universidad Nacional Mayor de San Marcos (Lima/Perú). Entre sus publicaciones recientes tenemos: "Ejército, política y sociedad en el Perú, 1821-1879", Trashumante. Revista Americana de Historia Social, No 12 (2018) y "De la reforma militar a la construcción del Estado: el ejército peruano en la transición de los siglos XIX y XX, PolHis, Año $10 \mathrm{~N}^{\circ}$ 20 (2018). Entre sus temas de interes están: Estado, Ejército, Historia conceptual, Imaginarios políticos, Cultura política.

Recibido: 30 de marzo de 2019

Aprobado: 9 de mayo de 2019

Modificado: 26 de mayo de 2019

Artículo de investigación científica

DOI: http://dx.doi.org/10.15648/hc.35.2019.8

Este artículo forma parte del proyecto “La modernización del Estado en el Perú, 1830-2010”, financiado por la Universidad Nacional Mayor de San Marcos (Lima/Perú).

Esta publicación está bajo una licencia Creative Commons Reconocimiento-NoComercial 4.0 
La reforma de la conscripción en el Perú en el tránsito del siglo XIX al XX. La aplicación de la Ley del Servicio Militar Obligatorio de 1898

\title{
Resumen
}

El presente artículo busca analizar la reforma de la conscripción que se produjo en el Perú a inicios del siglo XX con la aplicación de la Ley del Servicio Militar de 1898. Nuestra propuesta es que si bien, la aplicación de la ley modificó las viejas prácticas decimonónicas de constitución compulsiva o negociada de los ejércitos caudillistas, ella no pudo cumplirse con total estrictez debido a las limitaciones administrativas y coercitivas del Estado y la resistencia de diversos grupos sociales. Aun así, la norma permitió la constitución de grandes unidades militares de una forma burocrática y centralizada.

Palabras clave: servicio militar obligatorio, ejército peruano, conscripción, reforma militar.

Conscription Reform in Peru in the transition from the 19th to the 20th century. The application of the Compulsory Military Service Act of 1898

\begin{abstract}
This article seeks to analyze the reform of the conscription that occurred in Peru in the early twentieth century with the application of the Military Service Act 1898. Our proposal is that although the application of the law modified the old nineteenth-century practices of compulsive or negotiated constitution of the caudillistas armies, it could not be fulfilled with total strictness due to the administrative and coercive limitations of the State and the resistance of diverse social groups. Even so, the norm allowed the constitution of large military units in a bureaucratic and centralized manner.
\end{abstract}

Keywords: Compulsory military service, Peruvian Army, conscription, military reform.

A reforma do alistamento no Peru no trânsito do século XIX para o século XX. A aplicação da Lei do Serviço Militar Obrigatório de 1898

\section{Resumo}

Este artigo procura analisar a reforma do recrutamento que ocorreu no Peru no início do século XX com a aplicação da Lei do Serviço Militar de 1898. Nossa proposta é que, embora a aplicação da lei tenha modificado as velhas práticas do século XIX, Consti- 
tuição compulsiva ou negociada dos exércitos caudilhistas, não pôde ser cumprida com total rigidez devido às limitações administrativas e coercitivas do Estado e à resistência de diversos grupos sociais. Mesmo assim, a norma permitiu a constituição de grandes unidades militares de maneira burocrática e centralizada.

Palavras chave: Serviço militar obrigatório, Exército Peruano, alistamento militar, reforma militar

La réforme de la conscription au Pérou pendant le passage du 19ème au 20ème siècle. L'application de la Loi du Service Militaire Obligatoire de 1988

\section{Résumé}

Cet article cherche à analyser la réforme de la conscription qui a eu lieu au Pérou au début du XXe siècle avec l'application du Military Service Act 1898. Notre proposition est que, bien que l'application de la loi ait modifié les anciennes pratiques du dix-neuvième siècle constitution compulsive ou négociée des armées caudillistas, elle ne pouvait être remplie avec une stricte rigueur en raison des limites administratives et coercitives de l'État et de la résistance de divers groupes sociaux. Néanmoins, la norme permettait la constitution de grandes unités militaires de manière bureaucratique et centralisée.

Mots-clés: Service militaire obligatoire, Armée péruvienne, Conscription, Réforme militaire.

\section{INTRODUCCIÓN}

En los últimos años, la historiografía hispanoamericana ha visto un nuevo despertar de las investigaciones relacionadas con la historia de la guerra. Dejados atrás los estudios de la vieja historia militar, recientemente somos testigos de un mayor ímpetu por comprender el papel de la guerra, los ejércitos y los hombres de uniforme en la configuración de los Estados republicanos. La nueva historiografía sobre la guerra trata de superar la también vieja dicotomía de las relaciones cívico-militares prevalente en los estudios de ciencia política y la sociología, proponiendo diversos nexos entre la guerra, la cultura política, el Estado y la economía. Los avances en ese sentido han sido importantes, aunque siempre insuficientes, pues el 
acento de esta renovada historiografía ha tendido naturalmente a centrarse en el siglo XIX y especialmente, en la guerra fundacional de América Latina, la Independencia ${ }^{1}$. Pocos son los estudios aún abocados al siglo XX y más reducidos aún son los que tratan el servicio militar ${ }^{2}$.

Pese a que la manera por la cual los jefes militares logran "enrolar" a los hombres para la guerra es un asunto medular para la constitución de cualquier fuerza armada, este es un tópico poco explorado para la región. Sabemos de manera general que, en la historia de América Latina, las formas que adoptó este impuesto de sangre variaron desde la implantación de las milicias borbónicas en el siglo XVIII, se adaptaron o entraron en conflicto con las formas republicanas decimonónicas, y derivaron en muchos países en servicios militares obligatorios basados en el ejercicio de la ciudadanía. Lamentablemente, sabemos aún muy poco de estas transiciones.

En este artículo pretendo contribuir a llenar este vacío para el caso peruano. Me propongo explicar de qué manera la aplicación de la Ley del Servicio Militar Obligatorio de 1898 logró una militarización limitada de la sociedad peruana, modificando las antiguas formas clientelares y forzadas por las que se construían los ejércitos decimonónicos para reemplazarlas por un sistema centralizado y burocratizado organizado por el Estado. Para ello observaremos el diseño de la ley, la organización del Estado para su ejecución, sus limitaciones administrativas y coercitivas, así como las resistencias que esta norma generó, para luego llegar a un balance de su ejercicio en la primera década del siglo XX.

\section{LA Composición de LOS EJÉRCitos de CAUdillos EN EL SIGLO XIX}

A diferencia de los Estados europeos del siglo XIX ${ }^{3}$, cuando el Perú nació

1 Juan Carlos Garavaglia et al., Las fuerzas de guerra en la construcción del Estado: América Latina, siglo XIX (Rosario: Prohistoria, 2012); Juan Marchena y Manuel Chust (eds.), Por la fuerza de las armas. Ejército e Independencias en Iberoamérica (Castellón: Universidad Jaume I, 2007); Juan Ortiz Escamilla, Fuerzas militares en Iberoamérica, siglos XVIII y XIX (México: Colegio de México-Colegio de Michoacán-Universidad Veracruzana, 2005).

2 Carlos Camacho, "El reclutamiento, los soldados y la experiencia del cuartel: servicio militar obligatorio en Perú y Colombia (1919-1933)”, Revista de Indias, Vol. LXXVIII, No. 272 (2018): 263-287.

3 Para el proceso de construcción de las maquinarias militares europeas desde el siglo XVI, léase Geoffrey Parker, La revolución militar. Innovación militar y apogeo de Occidente 1500-1800 (Madrid: Alianza Editorial, 2002). 
como República no contaba con una larga experiencia militar. En la segunda mitad del siglo XVIII, fueron las milicias borbónicas el primer intento de crear una fuerza armada de importantes dimensiones que formalmente fluctuó entre 40 y 50 mil efectivos ${ }^{4}$. Constituidas sobre la base de la estructura de una sociedad virreinal, jerárquica, multiétnica y corporativa, su movilización no fue sino esporádica, sin significar una pesada carga para el gobierno colonial, ni una obligación abrumadora para los vasallos ${ }^{5}$. Y aunque fueron creadas para defender el Imperio español de la amenaza inglesa, lo cierto es que muchas de ellas recién se estrenaron cuando la crisis de la Monarquía española condujo a la descomposición del Imperio hispánico entre 1809 y $1824^{6}$.

Independizado el Perú, cupo al nuevo Estado construir su propio ejército. Instituido este según la legislación republicana, correspondía a los miembros de la comunidad política, como individuos-ciudadanos, prestar su fuerza para la defensa de la Patria como el más caro deber. No obstante, durante la mayor parte del siglo XIX, los procedimientos para sentar plaza poco tenían que ver con lo estipulado por la Constitución y las leyes. De manera gruesa se puede esquematizar que los ejércitos decimonónicos se compusieron por medio de cuatro vías: el reclutamiento, soldados voluntarios, la incorporación de guardias nacionales y la participación política de las montoneras.

En tiempos de paz, los gobiernos disponían el número legal de soldados que generalmente se computó entre 3.000 y 6.000 hombres, los cuales debían desgajarse de la población de los departamentos. Hecho ello, correspondía a los jefes de cuerpo de línea ajustar el número de plazas, ya sea dando de baja o de alta a los efectivos ${ }^{7}$. En un país como el Perú de-

4 Como observa Susy Sánchez, estos inflados volúmenes representaban efectivos potenciales ("en el papel"), antes que milicianos realmente movilizados. Susy Sánchez, "Civiles vestidos de militares", en Historias compartidas: economía, sociedad y poder, siglos XVI-XX. Actas del primer encuentro de historia Perú-Argentina (Lima: Instituto Riva Agüero, 2007).

5 John Fisher, El Perú borbónico 1750-1824 (Lima: Instituto de Estudios Peruanos, 2000), 80.

6 John Fisher, "Fidelismo, patriotismo e independencia", en La independencia del Perú ¿concedida, conseguida, concebida?, eds. Carlos Contreras y Miguel Glave (Lima: Instituto de Estudios Peruanos, 2015).

7 David Velásquez, "La reforma militar y el gobierno de Nicolás de Piérola, el Ejército moderno y la construcción del Estado peruano", (tesis Mg., Historia-UNMSM, 2008). 
cimonónico, donde la mayoría de la población era campesina e indígena (quechua y aymara hablante), existió un fuerte rechazo a entregar su reserva masculina en edad productiva por un período de tiempo determinado -en el mejor de los casos-, sin contraprestación concreta ${ }^{8}$. Las exigencias de este deber, a diferencia de lo que fue sucediendo en Europa a lo largo de la centuria, no venían acompañadas de verdaderas compensaciones en términos de derechos, en tanto los indígenas no disfrutaban de las mismas garantías y derechos que las poblaciones mestizas y criollas en las ciudades.

Para vencer esta resistencia, los agentes del Estado republicano ensayaron consistentemente el reclutamiento o leva, mecanismo por el cual los jefes de los cuerpos de línea comisionaban patrullas en poblados campesinos, principalmente serranos, para capturar hombres, jóvenes y adultos, sin las prelaciones exigidas por las leyes, para llevarlos compulsivamente a un cuartel en donde aprendían, también de manera violenta la vida mili$\operatorname{tar}^{9}$. No era este un procedimiento ejecutado privativamente en el campo, también en las ciudades -en momentos de guerra, donde apremiaba la constitución de contingentes- fue empleado y tildado por la prensa como "cacería de hombres"10.

En tiempos de guerra, internacional, pero sobre todo civil -cuando el ejército del gobierno era desafiado por el de un caudillo rival-, la necesidad de crear aceleradamente nuevas tropas, llevaba a los jefes militares peruanos, a añadir a la leva otros medios para componer sus huestes basados en la negociación. En algunos casos, los caudillos militares podían entusiasmar a los plebeyos (incluso indígenas) para vestir el uniforme, bajo la perspectiva de beneficios individuales, como el saqueo de una ciudad ${ }^{11}$. En otros,

8 El general Domingo Nieto mencionaba 1843, cómo la población indígena había desarrollado resistencias al reclutamiento: "Se recluta en los pueblos sin reparo, se cometen extorsiones de todo género por los comisionados. Cada reclutamiento deja escuetos los pueblos y puebla las quebradas naturalmente desiertas y los montes por muchos días". Carmen Mc Evoy, La Guerra Maldita. Domingo Nieto y su correspondencia (1834-1844) (Lima: Biblioteca Nacional del Perú, 2015, t. I) 337.

9 David Velásquez, "Indios, soldados sin patria: la conscripción militar en el Perú durante el siglo XIX”, Líneas Generales, vol. II (2018): 59.

10 En el contexto de la guerra que tuvo el Perú con el Ecuador (1860-1861) hubo diversas denuncias que en la propia Capital de la República se realizaba impunemente el reclutamiento. El Comercio. Lima, 5 de marzo de 1860; 12 de abril y 7 de junio de 1860; 6 de noviembre de 1861; y 26 de junio de 1864.

11 Flora Tristán, Peregrinaciones de una paria (Lima: Centro de la mujer peruana Flora Tristán-UNMSM, 2005), 426. 
lograban movilizar a las guardias nacionales, milicias que provenían del período virreinal y que durante el período republicano tenían una función principalmente defensiva. A diferencia de los cuerpos de línea, su acuartelamiento se realizaba solo durante períodos de inestabilidad ${ }^{12}$. No era raro que notables con ascendiente o capacidad de negociación en sus localidades, contaran con grados de guardia nacional, los cuales les permitían negociar con los caudillos nacionales la participación de sus subordinados en los conflictos decimonónicos ${ }^{13}$. Tampoco era raro, que jefes militares experimentados, como Domingo Nieto o Ramón Castilla, no sin persuadir personalmente a las poblaciones de la legalidad y conveniencia de sus causas, lograran su movilización ${ }^{14}$. Cerraban estas abigarradas fuerzas, las partidas de montoneros, compuestas por bandidos politizados, indígenas y peones de haciendas lideradas por sus patrones o por comunidades indígenas que, negociaban corporativamente, su participación, a cambio de beneficios como la exención de la contribución personal ${ }^{15}$. Sin duda, la circulación y posesión de armas de guerra entre la población civil permitió la participación de estos actores durante todo el siglo ${ }^{16}$.

Los ejércitos regulares peruanos eran pequeños en términos relativos si se comparan con los europeos decimonónicos que alcanzaban varias decenas e incluso centenares de miles de combatientes ${ }^{17}$; aunque se encontraban dentro de la regla de América Latina, en donde la ausencia de verdaderos desafíos internacionales inhibieron durante gran parte de la centuria una presión hacia la militarización de la región como ha observado Miguel

12 Hidalgo et al., Historia del Ejército en la República. Siglo XIX, t. V, vol. 1. La institucionalización del ejército: organización y evolución. (Lima: Comisión Permanente de la Historia del Ejército del Perú, 2005), 185.

13 David Velásquez, "La reforma militar y el gobierno de Nicolás de Piérola", 43-45 y 75-76.

14 Natalia Sobrevilla, "Ciudadanos armados: las guardias nacionales en la construcción de la Nación en el Perú de mediados de siglo XIX”, en Las armas de la Nación. Independencia y ciudadanía en Hispanoamérica (1750-1850), eds. Manuel Chust y Juan Marchena (Madrid: Iberoamericana-Vervuert, 2007), 178-179.

15 David Velásquez, "La reforma militar y el gobierno de Nicolás de Piérola", 76-78.

16 David Velásquez, "Una mirada de largo plazo: armas, políticas y guerras en el siglo XIX”, en Tiempo de guerra. Estado, nación y conflicto armado en el Perú, siglos XVII-XIX, eds. Carmen McEvoy y Alejandro Rabinovich (Lima: Instituto de Estudios Peruanos, 2018), 495-537.

17 William McNeill, La búsqueda del poder: tecnología, fuerzas armadas y sociedad desde el 1000 d.C. (Madrid: Siglo XXI Editores, 1988), 213-241. 
Ángel Centeno ${ }^{18}$. Además de las dificultades para movilizar a la población al frente de batalla que se salvaban con la participación de milicias y montoneras, un problema medular para el combate efectivo lo constituía la volatilidad de sus huestes. Para el caso de los soldados levados, la deserción podía llegar a ser masiva en momentos del combate, o peor aún los soldados amotinados podían desconocer la autoridad del caudillo y cambiar de bando. Esto último también era factible para las guardias nacionales y las montoneras, pues ante un revés en la guerra o por desacuerdos con los jefes, desconocían su liderazgo, se desmovilizaban o se pasaban al bando competidor ${ }^{19}$. Ningún caudillo podía asegurar la lealtad de sus hombres ni de sus aliados, sean jefes de guardias nacionales, hacendados o montoneros. Ejércitos así constituidos exigían negociaciones permanentes y equilibrios precarios que al romperse podían llevar a la disolución de cuerpos de tropa en pocas horas.

Ante este escenario, desde mediados de la centuria, cuando el Perú empezó a disfrutar una relativa pacificación, se hicieron intentos para normar de una manera regular la prestación del servicio. El presidente Ramón Castilla expidió la ley del 4 de enero de 1848 que estipuló que las altas del ejército debían cubrirse por medio del enganche y la conscripción. El enganche era un contrato por el cual el Estado pagaba una prima al soldado para que se diera de alta. Los espectaculares recursos que la explotación del guano ofrecía por esos años garantizaban el financiamiento de este método que la norma consideraba como el prioritario. En el caso que no se consiguieran las altas necesarias, la ley ordenaba que en las localidades se formara una junta compuesta por autoridades locales y los "padres honrados" (vale decir notales), a quienes les correspondía señalar como conscriptos a los que "no tengan ocupación ni se ejerciten en alguna industria ni sean útiles a sus familias"; y en el caso que no se cubriera la cuota señalada, se procedía al sorteo entre los jóvenes solteros y luego entre los casados. De acuerdo al

18 Los ejércitos de la región en tiempos de paz fluctuaban entre 2.000 y 5.000 efectivos, mientras que en guerra solo en pocas ocasiones superaron los 20 mil, como fue el caso de la Guerra de la Triple Alianza. Miguel Ángel Centeno, Sangre y deuda. Ciudades, Estado y construcción de nación América Latina (Bogotá: Editorial Universidad Nacional de Colombia, 2014), 322-326.

19 David Velásquez, "Ejército, política y sociedad en el Perú, 1821-1879", Trashumante. Revista Americana de Historia Social No. 12 (2018): 157. 
gobierno, estos mecanismos de alistamiento, además de pretender ser más eficientes y confiables, buscaban hacer cumplir los derechos y deberes de los ciudadanos-conscriptos ${ }^{20}$.

A pesar de estas buenas intenciones, las viejas prácticas no dejaron de emplearse, en tanto la pacificación del país no dejó de ser relativa, nuevos enfrentamientos entre caudillos demandaron la formación acelerada de fuerzas compuestas por cuerpos de línea, guardias nacionales y montoneras. Este fracaso era palmario en opinión del Ministro de Guerra de 1861, quien se quejaba que el enganche, además de ser un método sumamente costoso, no ofrecía soldados suficientes para el servicio e incluso estos no siempre contaban con buena constitución física ${ }^{21}$. En el caso de la conscripción, entregada a los notables locales, les otorgaba capacidad para decidir a su arbitrio quienes debían ser enviados a servir, de tal forma que "mand $[\mathrm{a}] \mathrm{n}[\ldots]$ á individuos que la suerte no señaló, ó como vagos perjudiciales al vecindario á personas con las cuales tienen algún motivo particular de disgusto" 22 .

En la década siguiente, cuando asumió la presidencia el primer político civil, Manuel Pardo (1872-1876), se trató nuevamente de reformar los instrumentos de conscripción. A diferencia de la anterior, la ley de 20 de noviembre de 1872 estableció por vez primera la conscripción general e igualitaria como método para reemplazar las bajas del Ejército. De acuerdo a ella, todos los jóvenes mayores de 21 años (exceptuados profesionales, religiosos, estudiantes y familiares de personas en estado de necesidad) debían ser sorteados para decidir su alta. Sin embargo, a similitud de la ley anterior, la nueva norma mantuvo el proceso de conscripción en manos de los notables locales por medio de las reactivadas municipalidades, sin que el gobierno central o los jefes militares tuvieran intervención. La ley estuvo lejos de cumplir sus objetivos, teniendo una limitada ejecución, pues, incluso durante el gobierno del mismo Pardo, las bajas del Ejército fueron

20 David Velásquez, "Indios, soldados sin patria", 61-62.

21 Memoria que el Ministro de Estado en el despacho de Guerra y Marina presenta al Congreso (Lima: Tipografía de Aurelio Alfaro y Cía, 1861), 19.

22 Memoria que presenta el Ministro en el despacho de Guerra y Marina al Congreso Nacional de 1862 (Lima: Imprenta de la Época, 1862), 62. 
reemplazadas a través del "enganche" 23 , pero también en varias provincias se recurrió al viejo reclutamiento ${ }^{24}$.

El precio pagado por el fracaso en organizar un sistema de conscripción regular y planificado fue la pérdida de los territorios de Tarapacá y Arica durante la Guerra del Pacífico (1879-1883). En este conflicto, como no podía ser de otro modo, se utilizaron los mismos mecanismos de los ejércitos caudillistas: levados, milicianos inexpertos, montoneros con lealtades precarias y, no cabe dudarlo, también ciudadanos que murieron o sobrevivieron para ver la derrota del Estado peruano ${ }^{25}$. Consecuentemente, las secuelas de la guerra modificaron sustancialmente las consideraciones sobre la conscripción militar. Durante los gobiernos del Segundo Militarismo (1884-1894) hubo una genuina preocupación por la reforma del Ejército, dándole especial atención a los problemas de la conscripción. De allí que, en el gobierno de Andrés A. Cáceres, se promulgara la ley de 15 de octubre de 1887 que reformaba la Guardia Nacional, transformándola en la reserva del Ejército permanente. Debía ser una fuente de conscriptos cuando las fuerzas del Ejército los requiriese y como unidades tácticas plenas integradas al Ejército nacional ante el contexto de una guerra internacional. Durante los años de su implementación, se llegó a registrar oficialmente 76 mil milicianos, aunque es probable que esta cifra fuera más formal que real, en tanto -como afirmaban los propios jefes militares- existían restricciones fiscales y falta de oficiales para su adecuado adiestramiento ${ }^{26}$.

El mérito de los gobernantes del Segundo Militarismo fue constituir un ejército del que los observadores de la época consideraron el mejor y más disciplinado hasta ese entonces ${ }^{27}$. Ello fue posible gracias a un atípico consenso entre los hombres de uniforme bajo la figura de Andrés A. Cáceres,

23 Manuel Pardo, "Mensaje como Presidente de la República al Congreso ordinario en el año 1876”, en La huella republicana liberal en el Perú. Manuel Pardo: escritos fundamentales, ed. Carmen McEvoy (Lima: Fondo del Congreso de la República, 2004), 468.

24 Respecto a ello, Ulrich Mücke muestra la imposibilidad del presidente Pardo de romper con las prácticas de reclutamiento en los departamentos serranos, donde los prefectos gozaban de una considerable autonomía frente a los requerimientos del poder central. Ulrich Mücke, Política y burguesía en el Perú. El Partido Civil antes de la Guerra con Chile (Lima: IFEA-IEP, 2010).

25 David Velásquez, "Indios, soldados sin patria", 61-63-65.

26 David Velásquez, "La reforma militar y el gobierno de Nicolás de Piérola", 303-304.

27 La Luz Eléctrica, Año V, N² 254, Lima, 7 de septiembre de 1895. 
un héroe de la Guerra del Pacífico, cuyo resultado fue la disminución de las rivalidades y luchas intestinas de la preguerra, pero que trajo como correlato la exclusión progresiva de los políticos civiles de la conducción del país. La re-militarización de la política incubó una paradójica alianza entre el Partido Civil y su principal enemigo, el también civil Nicolás de Piérola, quienes coaligados lanzaron una impresionante movilización armada que derrotó al ejército cacerista.

\section{LA REFORMA MILITAR Y EL DEBATE SOBRE LA CONSCRIPCIÓN A FINES DEL SIGLO XIX}

Iniciado el gobierno de Piérola (1895-1899) y habiéndose licenciado los restos del ejército de Cáceres, se abría una nueva oportunidad para la profesionalización y modernización del Ejército. Agobiados los uniformados por su derrota ante civiles y acusados de apropiarse del Estado, las condiciones para la reforma no pudieron ser más auspiciosas, coyuntura que Piérola aprovechó para emprender profundos cambios que sentaron las bases del ejército peruano moderno. Su objetivo y el de sus sucesores del Partido Civil fue domar políticamente a los jefes militares para convertirlos en defensores de la soberanía del Estado y garantes del orden interno. Para su logro, la coalición civil contrató una Misión militar francesa que, además de formar una nueva oficialidad, se convertiría en un conveniente aliado para emprender la transformación de la institución castrense. Los productos de la reforma fueron la profesionalización de una carrera de las armas, la creación de un sistema de justicia castrense, y el destierro de los métodos de constitución de fuerzas militares decimonónicas, reemplazándolas por una conscripción universal, burocrática y dirigida.

Sobre este último tópico se produjo en la prensa capitalina un interesante debate que antecedió la dación de la ley de conscripción de 1898, en el cual -a pesar de las diversas opiniones- hubo tres premisas compartidas. La primera consideraba necesaria la militarización de la sociedad peruana de cara a un aumento de la tensión fronteriza entre los Estados sudamericanos, en tanto constituir un ejército, de considerables dimensiones, formado por ciudadanos disciplinados e instruidos militarmente, resultaba ser 
una "póliza de seguros"28. La segunda planteaba la necesidad de establecer una institución que permitiera la militarización, pero que fuera compatible con las condiciones de la sociedad peruana: el tamaño de la población, sus actitudes frente al servicio militar, los principios republicanos y las necesidades de la economía peruana. La tercera consistía en determinar si las instituciones preexistentes eran ineficaces en el cumplimiento de su función ${ }^{29}$.

Respecto a la última premisa, existía un amplio consenso acerca de la deficiencia de la Ley de conscripción de $1872^{30}$ que no era extensible a la Ley de la Guardia Nacional del Segundo Militarismo. Una parte de los publicistas civiles y militares veía positivamente el modelo miliciano, el cual seguía siendo considerado como una "garantía de seguridad" del país ${ }^{31}$. Quienes estuvieron a favor de este punto expresaron que la Guardia Nacional se adaptaba mucho mejor a las condiciones de la segunda premisa, en virtud que el tiempo y las privaciones que esta exigía eran menores a los de una militarización total de la población como venía produciéndose en los países industrializados ${ }^{32}$. No obstante, uno de los argumentos a los que se le asignó mayor peso en favor del modelo miliciano consistía en que esta institución, a diferencia del Ejército, había permitido en el pasado mantener las diferencias y jerarquías sociales al interior de los cuerpos armados:

"[S]ería muy conveniente trasladar al Cuartel, en cuanto sea discretamente posible, las homogeneidades sociales con sus respectivas jerarquías; esto facilita la disciplina, trasladándola simplemente á las filas. El que manda y el que obedece se encontrarían en su centro normal, lo que vence las enormes dificultades y ries-

28 El Comercio, Lima, 16 de abril de 1898, edición de la tarde.

29 David Velásquez, "La reforma militar y el gobierno de Nicolás de Piérola", 306-308.

30 El coronel Tadeo Simeón Antay denunciaba los abusos que se cometían bajo el amparo de la norma de conscripción de 1872: aunque "prescribe el sorteo por quintas, ha producido pésimos resultados. [...] es una farsa, y si algo se aparenta cumplir, solo en las provincias atrasadas, se hace el sorteo al cálculo ó al tanteo.” El Comercio, Lima, 22 de abril de 1896, edición de la tarde.

31 La Opinión Nacional, Lima, 12 de febrero de 1898; El Comercio, Lima, 16 de abril de 1898, edición de la tarde.

32 El Comercio, Lima, 14 de marzo de 1898, edición de la tarde. 
gos de la diversidad de razas y costumbres en la aglomeración indistinta de los ciudadanos"33.

Tales argumentos demostraban que el servicio militar obligatorio estaba lejos de ser la opinión de mayor consenso, sin embargo, las discusiones se interrumpieron abruptamente en el segundo semestre de 1898, cuando se hizo público el debate en el Parlamento de un Proyecto de Ley para la institución del servicio militar obligatorio elaborado por una de las comisiones reformadoras creadas por el gobierno de Piérola. El proyecto del Gobierno modificó los términos de la discusión, por lo que, en adelante, sería sobre este proyecto que se discutiría cualquier método de militarización del país. En el Parlamento, senadores como Lorenzo Montoya consideraban que el servicio militar obligatorio era manifestación de la modernización del Ejército y una muestra del progreso del país, de allí que "[e]sta ley obedece, pues, á un plan bien ordenado del servicio militar conforme á las reglas del arte y al sistema moderno"34. Pero así también mostraron preocupación de que el servicio militar no afectara la vida de las actividades productivas y en especial la formación de los jóvenes profesionales, hijos de las familias acomodadas. En este último punto, los senadores mostraron con elocuencia su concepción particular -por decir lo menos- de la igualdad ciudadana: si bien, "todos los ciudadanos son soldados y están obligados á prestar sus servicios a la nación" 35 , la igualdad en el deber podía y debía cumplirse de forma diferente, en tanto que los grupos sociales del país lo eran así también ${ }^{36}$. Como manifestó el futuro presidente del país y miembro conspicuo de la oligarquía, Manuel Candamo, resultaba una feliz disposición del proyecto de Ley que los miembros de las clases acomodadas quedaran dispensados - por medio del pago de una prima militar- de la obligación de cumplir el tiempo del servicio permanente, deber ciudadano que podían cumplir con dinero:

"En el Perú, por la desigualdad de razas, entre las que predomina la de color; y más que eso, por la diferencia de educación,

33 La Opinión Nacional, Lima, 24 de marzo de 1898.

34 Cámara de Senadores (Lima: Imprenta de El Comercio, 1898), 114.

35 Esta fue, por ejemplo, la opinión del senador Montoya. Cámara de Senadores, 113.

36 Pueden leerse las opiniones del senador Emilio Luna al respecto. Cámara de Senadores , 115-116. 
sería poco práctico que se obligara á entrar en el sorteo á jóvenes de distintas condiciones. La obligación pesa siempre sobre ellos; pero la cumplen con el pago de la multa. No pasa lo mismo en Europa, en donde la raza es uniforme y la educación casi igual. [...] El que tiene fortuna cumple sus obligaciones con dinero.

[...] Creo, pues, que ese artículo es el más aceptable del proyecto" ${ }^{37}$.

De esta forma se conciliaba una nueva institución ciudadana, universal y obligatoria, con las preocupaciones sobre la necesidad de mantener las diferencias y jerarquías sociales en el Perú.

\section{El diseño y la aplicación de la Ley del Servicio Militar de 1898}

La Ley del Servicio Militar Obligatorio de 1898 fue la primera norma que instituyó, de manera regular y planificada, la prestación del servicio de las armas en la historia republicana. A diferencia de sus predecesoras, estaba diseñada para la constitución de grandes ejércitos que permitieran la instrucción metódica y la movilización masiva y centralmente dirigida de la población peruana en caso de un enfrentamiento militar. En virtud de ella, el ejército peruano quedó dividido en cuatro componentes: el ejército regular, los supernumerarios, las reservas y la Guardia Nacional. El primero resultaba ser el Ejército Permanente, compuesto por los soldados en actividad, conscriptos jóvenes de 19 a 23 años que, inscritos en los registros militares, eran designados por medio de un sorteo; los voluntarios, individuos de la misma edad que desearan ingresar a las filas; y, los enrolados, aquellos que omisos al registro o al sorteo eran castigados con el ingreso inmediato al Ejército ${ }^{38}$.

En virtud que el Ejército regular en la primera década del siglo XX no excedió las 4.000 plazas, la mayoría de jóvenes peruanos entre 19 y 23 años quedaba en condición de supernumerarios, ciudadanos considerados

$37 \quad$ Cámara de Senadores, 115.

38 Ley del Servicio Militar Obligatorio del 27 de diciembre de 1898. 
como parte efectiva del Ejército permanente, pero que no se encontraban en servicio activo. Estos eran sucedidos por las reservas: la primera, compuesta por licenciados del Ejército con edades entre los 23 y 30 años y los que en edad de entre 19 y 23 años estuvieran casados o fueran estudiantes de universidades y escuelas técnicas nacionales; la segunda estaba integrada por hombres mayores de 30 y menores de 35 años, así como por los directores y docentes de instituciones educativas, con edades de 19 a 35 años. Finalmente, la Guardia Nacional incluía a los hombres adultos entre los 35 y 50 años y los exceptuados de los otros grupos por su profesión, cargo público o condición familiar.

Los soldados del Ejército regular eran la base de la organización militar, les correspondía ser la primera línea de defensa del Estado en el exterior y de seguridad interior. Los conscriptos sorteados debían servicio durante tres años en la Infantería o cuatro para los cuerpos caballería y artillería, al cabo de los cuales eran licenciados y pasaban a la primera reserva. En caso de guerra exterior, el Ejército regular debía aumentarse, primero, con los supernumerarios, y luego, con la primera reserva. Por su condición de fuerzas de inminente movilización, ambos grupos debían ser instruidos militarmente, acuartelándolos hasta por dos meses. Cuando estas fuerzas resultaran insuficientes, se llamaba a la segunda reserva, mientras que la Guardia Nacional asumía la defensa de las circunscripciones militares a las que pertenecieran. Esta forma de organización, que dividía al total de población masculina por grupos étareos y los disponía metódicamente para afrontar una situación de guerra exterior, es lo que los actores de la época llamaban ejército "moderno", pues era "un verdadero engranaje" que incorporaba a "todos los ciudadanos según su edad, estado y ocupación" 39, organizándose "no solamente el ejército y la guardia nacional, sino que se organiza todo el país, en forma de ejército efectivo" 40 . Era, sin duda, el modelo de conscripción universal que se extendió en Europa y los Estados Unidos a partir del último tercio del siglo XIX.

39 Dictamen de las Comisiones de Guerra y Marina sobre el Proyecto de Ley de Servicio Militar Obligatorio de 1898. Cámara de Senadores, 110.

40 Declaración del senador Emilio Luna durante el mismo debate. Cámara de Senadores, 114. 
Para el logro de este fin, la Ley encargaba los actos de la conscripción a tres instituciones que debían establecerse a nivel nacional: la Junta de Inscripción de Distrito, la Junta Conscriptora de Provincia y la Junta Revisora. La primera era una institución local, compuesta por el Gobernador, el Alcalde y un Juez de Paz (nombrado por el Subprefecto), a la cual le correspondía tomar la inscripción de los ciudadanos obligados por la Ley radicados en el distrito. Los registros debían consignar los datos personales del ciudadano: nombre, edad, ocupación, lugar de nacimiento, estado civil, constitución física y la presencia de defectos corporales. La información era elevada ante la Junta Conscriptora, compuesta por el Juez de Paz, un síndico municipal, un militar desde el grado de capitán, el médico titular de la provincia y el Subprefecto que hacía de presidente de la Junta ${ }^{41}$. Esta institución era medular en el sistema, pues, además de rectificar los datos recibidos desde los distritos, ejecutaba el sorteo anual de los jóvenes de la provincia que pasarían a la condición de conscriptos en el Ejército regular y los supernumerarios. Asimismo, le correspondía calificar que los conscriptos sorteados cumplieran con los requisitos expresados en la Ley (como la edad y estado civil, la complexión física y la salud), así como el dispensar a los exceptuados ${ }^{42}$. Como garantía para los ciudadanos, la Ley y el Reglamento disponían que las personas disconformes de la calificación podían elevar un recurso a la Junta Revisora, institución compuesta por el Juez de Primera Instancia, el Alcalde municipal, un médico o un empírico, el párroco de la iglesia matriz y un militar.

Una constatación importante del diseño de la norma es que si bien las instituciones relacionadas con la conscripción incorporaban a diversas autoridades y profesionales locales y provinciales, a diferencia de las normas de 1848 y 1872, su funcionamiento exigía la intervención de autoridades designadas por el Ejecutivo (gobernadores, subprefectos y militares) con las cuales se buscaba cautelar que los intereses del Gobierno no fueran

41 Reglamento de la Ley de Servicio Militar Obligatorio de 1900. Ley de Servicio Militar Obligatorio de 1898.

42 En el sorteo, los jóvenes de 19 años debían extraer personalmente de un ánfora boletas numeradas, las cuales indicarían la prioridad de los ciudadanos en el llamamiento: aquellos que obtuvieran los números más bajos serían destinados al Ejército regular hasta cumplir la cantidad de hombres exigida por el Ejército, mientras que los individuos con los números siguientes debían quedar en calidad de supernumerarios. 
eludidos por los actores locales importantes. Sin embargo, para los gobiernos de la República Aristocrática (1899-1919), esta moderada gravitación resultó insuficiente, en tanto que tomaron medidas para crear progresivamente una burocracia militar destinada a dirigir, vigilar y sancionar las tareas de las instituciones de conscripción locales. En primer lugar, en 1901, la administración de Eduardo López de Romaña decidió reorganizar el Estado Mayor General (en adelante EMG), otorgándole la responsabilidad de dirigir y cautelar de manera centralizada y permanente, las tareas referidas al llamamiento y movilización de los conscriptos. Desde esa fecha, un EMG bajo el liderazgo de Paul Clément (jefe de la primera misión militar francesa) le correspondió establecer el número anual de conscriptos, prescribir los lineamientos generales de las operaciones de conscripción, y supervisar, orientar y fiscalizar por vía telegráfica las operaciones realizadas por los subprefectos y gobernadores, y buscar la sanción y reparación del incumplimiento de la ley ${ }^{43}$.

Por debajo del EMG, se fue creando además una burocracia nacional con la finalidad de acompañar, rectificar y vigilar in situ el proceder de las juntas conscriptoras y las de registro. Claramente, no existía confianza en los miembros de origen civil de estas instituciones, ni en los funcionarios políticos (subprefectos y gobernadores). En virtud de ello, primero, se constituyeron comisiones militares, por las cuales se destinaba a oficiales militares para recorrer los distritos y provincias de más de un departamento $^{44}$. La circular del Ministerio de Guerra y Marina del 25 de febrero de 1901 era muy ilustrativa a este respecto: " $[\mathrm{L}] \mathrm{a}$ extensión del territorio y los inconvenientes que por la distancia presenta una dirección central, conviene ensanchar, en cuanto sea posible, el radio de acción, vigilancia y ejecución: á este fin obedece el nombramiento de Comisiones militares con instrucciones detalladas para hacer ejecutar la ley"45.

Pronto esta disposición se consideró imperfecta y ya, para 1905, se inició

43 David Velásquez, "La reforma militar y el gobierno de Nicolás de Piérola", 336-337.

44 Decretos del 14 y 15 de febrero de 1901, en Memoria del Ministro de Guerra y Marina (Lima: Imprenta Liberal, 1901), 56-58.

45 Decreto del 15 de febrero de 1901, en Memoria del Ministro de Guerra y Marina (Lima: Imprenta Liberal, 1901) 57-58. 
la demarcación militar del territorio de la República, instituyéndose tres estados mayores regionales dependientes del EMG. La nueva organización se estableció de acuerdo a una demarcación con niveles jerárquicos: tres circunscripciones amplias que se llamaron "regiones militares" (Norte, Centro y Sur); al interior de ellas, subdivisiones nombradas "circunscripciones", que congregaban en la mayoría de casos a más de un departamento; mientras que el último nivel se superponía al territorio de las provincias. Esta demarcación vino acompañada de la constitución de una verdadera burocracia permanente destinada a la organización militar de la población en caso de necesidad de movilización de cara a un conflicto bélico. Según el jefe del EMG, para 1905, la ejecución del Ley de Servicio Militar era aún "irregular, ocasionando usurpaciones y abusos, ya en la formación de los registros, ya en la corrección de los sorteos, ya en la exactitud, en fin, en la reunión de los contingentes"; abusos u omisiones que solo se podría combatir con "la intervención y auxilio de ciertos funcionarios [militares]" El montaje de esta estructura fue sumamente complejo y difícil, considerando los límites presupuestarios y organizativos del pequeño Estado peruano de principios del siglo XX.

Así con todo, por medio de estos procedimientos, entre 1901 y 1910, se logró incorporar en el Ejército permanente a 20.000 hombres. Los llamamientos anuales de conscriptos fueron de 1000 y 2000 efectivos, lo cual significaba una presión de 0.07 y $0.14 \%$ sobre una población masculina que se computaba en 1365 895, según el censo de 1876. Aunque el Ejército permanente mantenía dimensiones similares a las del siglo XIX, durante este período, el peso del llamamiento se distribuyó proporcionalmente entre los distritos del país, lo que implicaba una ruptura de las inveteradas prácticas de reclutamiento por las cuales la casi totalidad del Ejército era extraída de los pueblos y caseríos serranos. Si bien el rosto del soldado siguió siendo indígena (serrano), ello se debía - esta vez- a que dicha población era mayoritaria en el país (cerca del 60\%). Sobre un llamamiento de mil conscriptos, los departamentos serranos como Ancash, Cuzco, Junín y Puno - desde donde en el pasado provenían casi la totalidad de levados230 otorgaban juntos el 38\% del contingente (104, 104, 79 y 101 conscriptos,

46 Memoria del Ministro de Guerra y Marina (Lima: Imprenta del Estado, 1905), LV. 
respectivamente), mientras que los predominantemente costeños de Ica, Lambayeque, La Libertad, Lima (incluyendo El Callao) y Piura, no dejaban de otorgar una cantidad importante que superaba el 20\% (24, 36, 58, 91 y 49). Por otra parte, cuando este porcentaje se distribuía en los distritos, la mayoría menores de 1.000 a 1.500 habitantes, el número de jóvenes destinados al servicio no superaba a uno o dos individuos, esto es, entre el $0,01 \%$ o el $0,02 \%$ de su población total. En ese sentido, la aplicación de la norma buscó distribuir más equitativamente el número de conscriptos sobre la población del país ${ }^{47}$.

\section{Las limitaciones de la implementación de la Ley del Servicio MilitaR}

La norma tuvo una serie de limitaciones propias de la implementación de una institución compleja, aplicada en una sociedad marcadamente rural y disgregada en un amplio territorio, y ejecutada por medio de un Estado con reducidas - aunque ascendentes- capacidades administrativas y coercitivas. Ejecutar irrestrictamente sus disposiciones chocaba con las limitaciones estructurales del propio Estado, las cuales debían vencer los desafíos de su territorio y los múltiples intereses y prácticas que plantearon fuertes resistencias al interior de los espacios locales.

La primera dificultad estribaba en la base de todo el procedimiento, la constitución de los registros militares. La norma disponía que los gobernadores debían empadronar a la población masculina hábil a nivel del distrito. No es difícil imaginarse su falta de diligencia, en tanto eran autoridades que además de carecer de sueldo no tenían emolumento por esta función. Por ejemplo, el Subprefecto de Huánuco excusaba el retraso de las tareas de registro provincial "por la ignorancia y demora de los gobernadores á la mayor parte de los que hubo que devolverles mal hecho" ${ }^{48}$. Este defecto no era privativo de aquella provincia, muy por el contrario, era una situación extendida, como se consignaba en un informe emitido por los

47 David Velásquez, "La reforma militar y el gobierno de Nicolás de Piérola", 341-342.

48 "Informe del Subprefecto de Huánuco, Manuel E. Robles, al Prefecto del departamento de Huánuco" (12 de mayo de 1906), en Archivo Histórico Militar del Perú (de ahora en adelante, AHMP), Caja N. ${ }^{\circ} 8$. 
responsables del viaje de estudios de la Escuela Superior de Guerra en los departamentos de La Libertad, Cajamarca, Lambayeque y Piura entre 1905 y $1906^{49}$.

Correspondía a la Junta Conscriptora rectificar los registros militares, no obstante, en la práctica los trabajos reales recaían en los subprefectos, quienes eran las únicas autoridades permanentes de estos cuerpos colegiados. Para el cumplimiento de esta función, los gobiernos de la primera década del siglo XX no asignaron personal estable, y solo se cumplía si el subprefecto contrataba un amanuense que podía ser rentado con la recompensa pecuniaria que el Ejecutivo otorgaba en el caso que los documentos estuvieran conformes. Sin duda, la práctica de asignar fondos ex post buscaba generar estímulos para el cumplimiento de la Ley, pues, varios subprefectos no se hicieron acreedores de tal recompensa y tuvieron que rectificarlos o pagar de su peculio la tarea de su confección. No obstante, el no contar con personal especializado y permanente, sin duda, dificultó la acumulación de la experiencia administrativa para llevarla a cabo ${ }^{50}$.

$\mathrm{Y}$ aunque las condiciones administrativas hubieran sido óptimas, los registros de conscripción no podían reflejar a la población hábil del país en su integridad. El Estado carecía de instrumentos para conocer el tamaño de su población (no se tuvo un censo actualizado sino hasta 1940) y de un sistema nacional de registro civil que permitiera identificarlos por edades y estado civil ${ }^{51}$. Para la época, pocas municipalidades contaban con oficinas de registros civiles y las que las poseían, no siempre tenían su información actualizada. Por su parte, sus sucedáneos, los registros parroquiales, en muchos casos también eran incompletos y defectuosos ${ }^{52}$. Por ello, se presentaron varios casos de resistencia de municipalidades y párrocos de

$49 \quad$ El comandante Jacques Romieux, miembro de la Misión Francesa, después de hacer diversas averiguaciones concluía que "las operaciones de la Junta Inscriptora cuya composición (Gobernador, etc.) no da garantía ninguna de exactitud á las inscripciones, base de todo [el] sistema". "Informe sobre la aplicación de la Ley de Servicio Militar Obligatorio en zona recorrida durante el viaje de estudios de la Escuela Superior de Guerra" (1905), en AHMP, Caja N. . 4, fol. 5.

50 David Velásquez, "La reforma militar y el gobierno de Nicolás de Piérola", 345-347.

51 "Informe sobre la aplicación de la Ley de Servicio Militar Obligatorio en zona recorrida durante el viaje de estudios de la Escuela Superior de Guerra” (1905), en AHMP, Caja N. ${ }^{\circ}$ 4, fol. 4.

52 David Velásquez "Una historia de los registros del estado civil en el siglo XX, en RENIEC, identidad digital. La identificación desde los registros parroquiales al DNI electrónico (Lima: RENIEC, 2015), 537-567. 
mostrar las actas de nacimiento/bautismo, matrimonio y defunción, el cual era el material necesario para la rectificación de los registros militares $^{53}$. Dificultaba también la facción de los registros militares las propias actitudes de la población respecto al servicio, que mostraban rechazo y temor, sobre todo en las poblaciones de carácter indígena ${ }^{54}$.

Ahora bien, no solo hubo limitaciones en la inscripción, los otros procesos relativos a la conscripción mostraron también defectos, ya sea por la omisión, falta de diligencia o deliberada acción de los funcionarios en el momento de realizar el sorteo y la calificación de los conscriptos. Los subprefectos, como únicas autoridades administrativas, excusaron reiteradamente estos defectos en la multiplicidad de responsabilidades políticas y militares que tenían a su cargo, a lo que debía añadirse (en favor de ellos) que pocos subprefectos permanecían en sus puestos más de un año ${ }^{55}$. Si estas limitaciones tenían los subprefectos, a quienes se les conminaba desde el Ministerio de Guerra y Marina y del de Gobierno, o se les castigaba con penas pecuniarias, menor era el empeño de los otros miembros de las Juntas Conscriptoras, como lo menciona el coronel Justiniano Borgoño:

“éstas [Juntas Conscriptoras] salvo honrosas excepciones, apenas si se preocupan de llenar sus sagrados deberes. En verdad los únicos que trabajan son los amanuenses-archiveros, bajo la dirección del Subprefecto, cuando es pundoroso y digno. Ni el Juez de Paz, ni el Síndico municipal, ni el médico titular llenan fielmente su cometido. Se reúnen rara vez, no conocen porque no se contraen á estudiarlas, la ley, el reglamento y las instrucciones; ni ayudan a la facción de los documentos, porque la consideran pesada y dificultosa, porque desde que no les reporta utilidad pecuniaria, no quieren sacrificar su tiempo"56.

53 David Velásquez, "La reforma militar y el gobierno de Nicolás de Piérola", 349.

54 El prefecto de Ayacucho informaba al Ministerio de Gobierno que: "La Ley de servicio militar es una de las de más difícil aplicación en nuestros Departamentos del Interior: creen los indios que por el hecho de estar vestidos de soldados están más inmediatos á la muerte”, Memoria del Prefecto de Ayacucho J. Álvarez Páez, 1902, 30.

55 David Velásquez, "La reforma militar y el gobierno de Nicolás de Piérola", 352.

56 Justiniano Borgoño, Memoria que presenta al Sr. General Jefe de E. M. General del Ejército. El Jefe de la Comisión Militar de los Departamentos de Lima, Ica, Junín y provincia constitucional del Callao. Año de 1902 (Lima: Imprenta La Industria, 1902), 11. 
Resultaba especialmente capital para la conscripción la calificación de los sorteados, acto que debía hacerse atendiendo los documentos que acreditaran el estado civil, la edad, la profesión, la salud y la aptitud física de los conscriptos. Para regular el proceder de los subprefectos en este punto se diseñó un sistema de premios y castigos, por medio de gratificaciones y medidas correctivas, como penalidades pecuniarias, solicitudes de suspensión o destitución, e incluso juicios militares. En muchos casos, cuando se demostraba que el subprefecto o la Junta Conscriptora había remitido a exceptuados por la ley, estos eran devueltos a sus hogares a cargo del sueldo del subprefecto. En la segunda mitad de la década, el número de inobservancias de calificación a cargo de los subprefectos decayó ostensiblemente, situación que no se producía con la calificación de salud y estado físico ${ }^{57}$. Para esta, la Ley había incluido en la junta de conscripción al médico titular de la provincia, quien debía realizar los reconocimientos médicos de los conscriptos, sin embargo, esta resultó ser una disposición incompatible con la realidad, pues el número y distribución de profesionales de la salud en el territorio nacional no se encontraba acorde con las dimensiones del proceso de conscripción. Aunque la ley previó esta insuficiencia, su alternativa no fue mejor, pues facultaba que los reconocimientos fueran realizados por empíricos, quienes no tenían verdaderos conocimientos de medicina ${ }^{58}$. Y aún en casos en que los médicos realizaban la calificación, el establecimiento de un segundo reconocimiento en la Capital y la adquisición de un laboratorio bacteriológico, ya en 1906, por el Instituto de Sanidad Militar, demostró que los galenos, o no estaban en capacidad de hacer el reconocimiento con total fiabilidad o lo hacían con dejadez. Es por ello que la principal razón para el retorno de conscriptos a sus hogares en la segunda mitad de la década de 1910 se debió a la deficiente calificación física; muchos conscriptos llegaban a la capital con defectos físicos o enfermedades crónicas y contagiosas. Entre 1904 y 1908, el porcentaje de conscriptos licenciados por enfermedades fluctuó entre el 5,9 y el $15,3 \%$ del tota $1^{59}$.

57 David Velásquez, "La reforma militar y el gobierno de Nicolás de Piérola", 382-386.

58 Por ejemplo, el Prefecto de Yauyos informaba en 1907 que "[e]l empírico nombrado por la Junta Conscriptora [...] me ha manifestado que no responde de la certeza de sus certificados por cuanto carece de los conocimientos necesarios que sólo se adquieren en la facultad de medicina". "Oficio del Prefecto de Lima, Julio Jiménez, al Director de Guerra” (17 de mayo de 1907), en AHMP, Caja N. ${ }^{\circ} 8$.

59 David Velásquez, "La reforma militar y el gobierno de Nicolás de Piérola", 353-357. 
Finalmente, el tercero de los inconvenientes organizativos radicaba en las limitadas capacidades para el ejercicio de la coerción del Estado en los espacios locales, especialmente en las zonas rurales. Una vez que los jóvenes eran sorteados debían presentarse voluntariamente en la capital de la provincia para ser conscriptos. En una multiplicidad de casos, diversos grupos sociales fueron reticentes a entregar a sus jóvenes al Ejército, siendo esto especialmente cierto para las comunidades indígenas. La visión de estos sobre el Ejército no había cambiado a pesar de la modificación de los procedimientos de alistamiento militar, como anotaba el Prefecto de Ayacucho en $1902^{60}$. Para el caso de estos omisos, la ley prescribía que la pena era la captura y el enrolamiento inmediato, tarea que correspondía en los distritos a los gobernadores y las fuerzas de policía. Sin embargo, durante el tiempo de la ejecución de la norma, en muchos distritos pequeños y rurales, el único representante del Estado era el gobernador, el cual no contaba normalmente con efectivos a su cargo para respaldar su autoridad. A fines del XIX y el temprano siglo XX, el número de efectivos de la policía (guardia civil y gendarmería) no superaba los 6.000 hombres, los cuales se concentraban en las capitales departamentales y en las principales ciudades, marchando solo de manera esporádica a sus distritos ${ }^{61}$. Para el caso de la persecución de los omisos, los gobernadores se encontraban al mismo tiempo, asilados frente a la población local - con la cual sin duda tuvieron tensiones y negociaciones-, así también podían actuar de manera brutal cuando disponían de la fuerza, ya sea cumpliendo la ley con los enrolados o simplemente ejecutando levas con sus rivales o con quienes tuvieran malquerencias locales. No deja de ser obvio que en estos casos tuvieron que haber puntos intermedios, pero tampoco deja de ser cierto que al percibirse un Estado que esporádica y brevemente intervenía en las poblaciones locales, aunque sus incursiones sean brutales, estas dejaban intersticios suficientes para el desconocimiento de sus mandatos.

$60 \quad$ Ver cita 54.

61 Por ejemplo, el Prefecto de Ayabaca daba cuenta, en 1905, que "mi despacho dispuso que el Comisario de esta Provincia D. Antenor M. Paz, saliese en comisión á los distritos, prestando su apoyo á los Gobernadores en la reunión del contingente por 1904". "Expediente de Eulogio Rojas y Córdova de la Provincia de Ayabaca para que se le exima del servicio militar obligatorio" (Piura, 8 de abril de 1905), en AHMP, 1906, Caja N. ${ }^{\circ}$. 


\section{LAS RESISTENCIAS AL SERVICIO MILITAR EN EL TEMPRANO SIGLO XX}

Resulta claro que la demanda de hombres por parte del Estado para el cumplimiento del servicio militar ofrecería resistencia de la población. La exigencia de acuartelar a individuos en una edad productiva por un período de tres o cuatro años significaba la pérdida de ese tiempo para quien se beneficiará de él. En primer lugar, afectaba a quienes vivían a expensas de su trabajo (por ejemplo, los jornaleros o artesanos en las ciudades) y que constituían un ingreso para las unidades familiares a las que pertenecían. Sin embargo, a pesar de ello, los casos de omisos en las ciudades importantes no fueron con el pasar del tiempo altas, especialmente en el caso de la capital. Situación diferente se producía en el campo, donde hacendados y comunidades indígenas campesinas planteaban importantes desafíos a los esfuerzos del Estado por extraer su reserva masculina.

Respecto a los primeros, el servicio militar implicaba la pérdida -sin compensación alguna- de fuerza de trabajo fijada a la hacienda o de jornaleros con los que se podía contar para las labores agropecuarias ${ }^{62}$. En el pasado, cuando los hacendados habían movilizado sus peones en las guerras, siempre lo habían hecho bajo beneficios clientelares, esporádicamente, por un tiempo limitado (a juicio del patrón), y sin perder el control sobre esta fuerza. Con la demanda del Estado que planteaba el servicio militar, al ser esta de manera compulsiva, hecha por un mandato impersonal e individualizada, los hacendados solo veían en ella perjuicio, pues significaba competir por mano de obra en un contexto en el que producía la recuperación de la agricultura de exportación en la costa y la expansión de la gran hacienda en la sierra sur. Aún más, en el caso de que los indígenas soldados regresasen a las haciendas luego de servir, los conocimientos aprendidos en el cuartel, como el español y la lectoescritura, además de un mayor

62 En Lambayeque, el Prefecto reportaba al gobierno en 1902 las resistencias de los hacendados para la conscripción de trabajadores enganchados en sus propiedades, los que constituían un número importante del total de los sometidos al deber del servicio: «gran parte de los inscriptos son peones de fundos rústicos, que según costumbre establecida, han recibido de sus patrones adelantos; los cuales, en guardia de sus intereses, los ocultan, impidiéndoles así el cumplimiento de sus sagrados deberes ciudadanos». "Memoria del Prefecto de Lambayeque de 1902" (Lima: Ministerio de Gobierno y Policía, 1902), 64. 
contacto con el mundo oficial, no podían menos que ser incómodos para los hacendados ${ }^{63}$.

Empero, no eran los hacendados los únicos que se resistían al servicio militar, los comuneros indígenas también buscaron eludir este deber. Los campesinos indígenas durante el siglo XIX, cuando habían prestado sus hombres voluntariamente a los ejércitos caudillistas, lo habían verificado de manera corporativa y negociada, por el corto tiempo que durase la campaña, siempre a cambio de una contraprestación también corporativa, estableciéndose entonces una relación clientelística entre el caudillo y la comunidad. Por el contrario, la nueva Ley ejercía su presión sobre individuos (sorteados), se hacía bajo el cumplimiento abstracto de un deber que no reportaba compensación tangible, y rompía los lazos familiares y comunitarios por un período de tiempo (de tres a cuatro años), que no podía ni negociarse ni modificarse.

Para eludir el servicio, la población rural desarrolló una serie de tácticas. La primera, fue huir de sus poblaciones al saber que habían sido designados por el sorteo o incluso antes. En 1902, el subprefecto de Huamachuco informaba que no había podido enviar hombres, porque "no ha sido posible descubrir el paradero de los conscriptos que fueron sorteados el año pasado" "64. También los jóvenes buscaron vulnerar el sistema a través de otras tácticas, como casarse, pues los casados de entre los 19 y 23 años pasaban inmediatamente a la primera reserva. En algunas localidades de Ayacucho, por ejemplo, los indígenas al conocer que el matrimonio los eximía -en alianza y connivencia con los párrocos locales- realizaron matrimonios masivos entre la fecha del sorteo y del llamamiento, de allí que "se presentaba un sorteado, al inscribirse como soltero, con los comprobantes de haber contraído matrimonio días antes del sorteo" ${ }^{65}$. En otras ocasiones,

63 En un sugerente ensayo, Cecilia Méndez llamó la atención acerca de los diversos casos en los que indígenas licenciados del Ejército se convertían en líderes de las comunidades campesinas en sus luchas contra los gamonales durante las dos primeras décadas del siglo XX

64 AHMP, 1902, Caja N. . 9, "Oficio de la Dirección de Gobierno a la Dirección de Guerra", del 4 de septiembre de 1902. Este oficio transcribe un oficio del Subprefecto de Huamachuco, del 7 de septiembre de 1902.

65 "Memoria del Prefecto de Ayacucho J. Álvarez Páez, 1902”, p. 30, en Ministerio de Gobierno y Policía (1902). 
los propios campesinos indígenas preferían engancharse en las haciendas bajo la protección de un hacendado, antes que servir en el Ejército ${ }^{66}$ o en otras resistir a viva fuerza las comisiones de conscripción y enrolamiento ${ }^{67}$.

No fueron infrecuentes las falsificaciones de documentos en complicidad con autoridades civiles, militares y eclesiásticas, tanto en las zonas rurales, como urbanas. Del mismo modo fueron importantes las relaciones personales y el estatus social para granjearse el favor de cualquiera de estas autoridades. Por ejemplo, dejó perplejas a las altas autoridades castrenses que, al convocarse a las maniobras de Lima de 1907, animados por el ambiente celebratorio y marcial, los estudiantes de la aristocrática Universidad de San Marcos que decidieron participar, ni siquiera estaban inscritos en los registros militares, lo que equivalía que no existían para el Ejército y, por ello, no debían pagar la prima militar. No era un caso solo de los hijos de los oligarcas limeños, en localidades como Chincha, hubo denuncias de favorecimiento de jóvenes de familias acomodadas que, habiendo salidos sorteados, fueron reemplazados por personas de menores recursos, algunos de los cuales estaban legalmente exonerados ${ }^{68}$.

\section{CONCLUSIÓN: UNA MILITARIZACIÓN INCIPIENTE}

Luego de ver la aplicación de la Ley del Servicio Militar Obligatorio de 1898, con sus limitaciones y resistencias, resulta ineludible preguntarse si ella alcanzó sus objetivos de militarización burocratizada de la sociedad peruana. En primer lugar, significó el fin de las formas de reclutamiento

66 El Subprefecto de la provincia serrana de Cajabamba reportaba que contratistas costeños enganchaban como peones en las haciendas del Valle de Chicama (Lambayeque) a muchos jóvenes indígenas, pues estos "todavía lo creen castigo [servir en el ejército], incitado[s] por estos enganchadores, [lo que] hace que los sorteados para verse libres del servicio militar, se comprometan á ir á trabajar á la costa, de tal manera que cuando hai que llamarlos al servicio están la mayor parte ausentes". AHMP, 1904, Caja N. ${ }^{\circ}$ 6, "Copia de oficio del Subprefecto de Cajabamba al Prefecto del departamento de Cajamarca", del 28 de enero de 1904.

67 Tal como sucedió en el distrito cuzqueño de Quipiscanchis en junio de 1902, donde sus pobladores eran acusados de "haber arrebatado á un conscripto que el Subprefecto [...] remitía á esta Prefectura". AHMP, 1902, Caja N. ${ }^{\circ}$ 10, "Oficio del Prefecto de Cuzco, Toribio Raygada, al Director de Guerra", del 16 de junio de 1902.

68 AHMP, 1901, Caja N. ${ }^{\circ}$ 5, "Solicitud de varios conscriptos de la provincia de Chincha", del 11 de noviembre de 1901. 
decimonónicas, pues la leva y las formas de alistamiento, vía negociación clientelar dejaron de ser el medio por el cual se llenaban las plazas del Ejército del siglo XX. De manera creciente, los procedimientos de la ley se convirtieron en el medio por el cual el Ejército peruano accedió a la reserva masculina. Ello no quiere decir, como hemos visto, que los objetivos de la ley se cumplieran a cabalidad. La norma formalmente se basaba en la universalidad de la ciudadanía, en el llamamiento de ciudadanos abstractos designados impersonalmente (por sorteo) que cumplían un deber que debía pesar de manera igualitaria sobre todos los varones jóvenes. Sin duda alguna, este objetivo no se cumplió, pues el propio diseño de la ley preveía una cláusula de excepcionalidad para los sectores acomodados (prima militar), lo que no negaba que estos sectores y otros que gozaran de influencias sociales y económicas dejaran de emplearlas para eximirse del servicio. Dicho esto, no cabe duda que la mayoría del Ejército peruano siguió componiéndose globalmente por jóvenes indígenas provenientes de las zonas rurales, pero ello, se debía más a su peso demográfico que por su total indefensión frente a los operadores de la conscripción. En gran medida, el llamamiento de conscriptos se basó en criterios demográficos que exigían una contribución en proporción al número de varones existente en los distritos del país, lo que equiparó, por un lado, la distribución regional de esta carga y, por otro, la hizo pesar de manera importante en los núcleos de mayor concentración de la población, como Lima y otras ciudades importantes, donde la población indígena no era mayoritaria.

A ello debe añadirse que, desde las altas autoridades del Ejército, especialmente cuando el EMG estuvo bajo la impronta de Paul Clément, hubo especial preocupación en el cumplimiento de los procedimientos que el propio jefe de la misión francesa ayudó a instituir. En esa dirección se fue constituyendo una burocracia militar (primero con comisiones y luego con los EMG regionales), la cual se convirtió en representante del gobierno central para dirigir, acompañar y fiscalizar el proceso de llamamiento. Adicionalmente, se creó un sistema de premios y castigos para obligar la observancia de la ley por parte de los subprefectos, lo cual produjo que las reclamaciones sobre este tipo de autoridad disminuyeran. Si esto implicaba el seguimiento más riguroso de la Ley por parte de las autoridades locales, no sucedió lo mismo con las calificaciones médicas de los cons- 
criptos, pues, como hemos visto, el número de los que fueron devueltos a sus hogares por enfermedades siguió siendo alto, incluso hasta fines del período que estudiamos.

Por último, vale la pena aquilatar el alcance del servicio militar obligatorio, es decir, cuántos hombres lograron ser registrados y movilizados en la primera década del siglo XX. Si recordamos las dificultades para la inscripción de la población en los registros militares, parecería que esta tarea fracasó, pues la reforma buscaba el total registro de la población hábil. Sin embargo, a fines de la primera década del siglo XX, incluso Paul Clément, para entonces jefe del EMG, consideraba con orgullo que después de diez años de aplicación de la norma se había logrado inscribir la cifra nada despreciable de 575. 238 "ciudadanos", que incluía licenciados del Ejército, supernumerarios, reservas y la Guardia Nacional. Esta cifra era muy superior a los 50 y 76 mil que se logró durante el virreinato y el Segundo Militarismo, y representaba el $42 \%$ de los varones registrados en el ya desfasado censo de $1876^{69}$. Y aunque los registros no eran perfectos, permitieron al Ejército peruano contar con un número de efectivos -identificados por nombre propio, edad y lugar de residencia- muy superior a sus exigencias regulares, si recordamos que el Ejército permanente no superó los 4.000 hombres $^{70}$.

Otra forma que permitió aquilatar a los propios actores de la época la efectividad de la reforma del servicio fue el llamamiento para maniobras y movilizaciones de contingentes que se hicieron en la segunda mitad de la década. En 1906 y 1907 se realizaron maniobras en Jauja-Concepción (departamento de Chorrillos) y el distrito capitalino de Chorrillos como ensayos dirigidos a la instrucción relámpago de los supernumerarios y reservas. Las primeras congregaron 1.556 efectivos de las provincias serranas

69 Paul Clément, Memoria del General Jefe del Estado Mayor General del Ejército (Chorrillos: Oficina tipográfica litográfica de la Escuela Militar, 1910), 24.

70 Por esta razón, en 1908, el Ministro de Guerra consideraba prudente cerrar por algún tiempo parte del registro, manteniendo solamente la inscripción de supernumerarios y primera reserva (grupos etáreos más jóvenes), pero al mismo tiempo tratar de hacer el registro más completo y riguroso, a fin de que se contase «con la seguridad de conocer siempre el paradero ó residencia de los inscritos de tal manera que se les pueda encontrar listos el día que se les llame» (MGM 1908: 5). 
de Huancayo, Jauja y Tarma, de los cuales, 500 fueron supernumerarios, otros 500 de la primera reserva y el resto voluntarios. Luego de un adiestramiento de tres semanas se realizaron las maniobras que, de acuerdo a Paul Clément, jefe del EMG, tuvieron notable éxito. Para las maniobras de Chorrillos, se convocaron 3.050 hombres de Lima, sus distritos y El Callao y aunque se tuvieron que realizar sobrecargados trabajos para revisar y arreglar los registros militares, el total de ciudadanos que se presentaron al llamamiento fue 12.722 sobre un total de 14.870 inscritos. Por el número de sus participantes, entre los que estuvieron los estudiantes de la Universidad de San Marcos (quienes no estaban originalmente inscritos), esta maniobra fue considerada como un nuevo éxito ${ }^{71}$, dado que en este ejercicio militar público y masivo "[l]a opinión pública parece también estar gratamente impresionada, por los esfuerzos que se están haciendo para dar al Ejército su verdadero carácter nacional"72.

Ambas maniobras no fueron sino preámbulos para las operaciones de movilización que se ejecutaron en 1909 y 1910 a raíz de tensiones por diferendos limítrofes que podían escalar a un enfrentamiento militar. En septiembre de 1909, las desavenencias irresueltas con Bolivia, obligaron a la formación de una "fuerte división" a la que se incorporaron cinco mil supernumerarios y reservistas, de los cuales dos mil provenían de los departamentos de Arequipa, Cuzco y Puno y tres mil de los departamentos de Junín, Lima y El Callao "principalmente á los [...] que hicieron su período de maniobras en 1906 en Jauja y en 1907 en Chorrillos" "73. En 1910, ante el peligro de una guerra con el Ecuador, se organizó en el norte un Ejército de alrededor veinte mil plazas, haciéndose el llamamiento de supernumerarios y reservistas de los departamentos de Lima, Junín, Puno, Cuzco y Arequipa, precisamente aquellos que habían participado en las maniobras de 1906 y 1907 y en la movilización de 1909, a los que se sumaron otros de los departamentos de Piura, Cajamarca, Lambayeque y La Libertad y los licenciados del Ejército, los cuales en total sumaron diecisiete mil plazas. La reunión del contingente se logró en dos meses, consiguiéndose la instrucción de alrededor doce mil hombres ${ }^{74}$.

71 "Memoria del Jefe del Estado Mayor del Ejército", en MGM (1907: 4-5).

72 AHMP, 1907, Caja N. ${ }^{\circ}$ 2, "Oficio del Jefe del EMG, Paul Clément, al Ministro de Guerra y Marina", del 24 de octubre de 1907.

73 Paul Clément, "Memoria del General Jefe del Estado Mayor General del Ejército", 23

74 Paul Clément, "Memoria del General Jefe del Estado Mayor General del Ejército", 7-8 y 23-24. 
Si la meta de la Ley del Servicio Militar Obligatorio propugnada por Piérola y diferentes actores a fines del siglo XIX había sido la militarización del país, las movilizaciones de 1909 y 1910 habían mostrado que, después de una década de constante trabajo de una burocracia centralizada y vigilante, esta era posible, permitiendo la defensa del país frente a una posible agresión externa. La movilización de importantes contingentes de hombres se logró en ambos casos, pero como había mostrado las maniobras de 1907 y la movilización de 1909, esta no podía conseguirse sin superar un sinnúmero de dificultades, como en el caso de Chorrillos, y que restaban eficacia a la organización militar del país. Tampoco fue un procedimiento aséptico, pues como mostraron los casos de las provincias serranas de Huancayo, Tarma, Cerro de Pasco y Yauli, se siguieron enviando en las grandes movilizaciones personas inhábiles por falta de médicos para sus reconocimientos, ni faltaron inobservancias a las excepciones como sucedió en Huancayo y Jauja ${ }^{75}$. Aun así, se puede concluir que la norma logró parcialmente su objetivo, es decir, alcanzó una militarización metódica, pero limitada del país.

\section{FuENTES}

\section{Fuentes documentales manuscritas}

Archivo Histórico Militar del Perú (AHMP)

1901, Lima-Perú, Cajas 5, 8

1902, Lima-Perú, Cajas 3, 7, 9

1904, Lima-Perú, Caja 6

1905, Lima-Perú, Cajas 4, 8, 14, 15

1906, Lima-Perú, Caja 1

1907, Lima-Perú, Caja 8

1909, Lima-Perú, Caja 1

\section{Periódicos}

El Comercio, Lima, 1860, 1861, 1864, 1872, 1896, 1898.

La Luz Eléctrica, Lima, 1895.

La Opinión Nacional, Lima, 1897, 1898.

75 AHMP, 1909, Caja N. . 1, "Oficio del Jefe del Estado Mayor del Ejército, Paul Clément, al Ministro de Guerra y Marina", del 26 de agosto de 1909. 


\section{Fuentes documentales impresas}

Cámara de Senadores (1898). Diario de los debates de la Honorable Cámara de Senadores. Congreso Extraordinario de 1898. Lima: Imprenta de El Comercio, 1898.

Clément, Paul. Legislación militar. Lima: Tipografía y Litografía de la Escuela Militar, 1900.

Clément, Paul. Memoria del General Jefe del Estado Mayor General del Ejército. Chorrillos: Oficina tipográfica litográfica de la Escuela Militar, 1910.

Ley del Servicio Militar Obligatorio del 27 de diciembre de 1898.

Memoria del Prefecto de Ayacucho J. Álvarez Páez, 1902. Lima: Ministerio de Gobierno y Policía, 1902.

Memoria del Prefecto de Lambayeque de 1902. Lima: Ministerio de Gobierno y Policía.1902.

Memoria del Ministro de Guerra y Marina 1904. Lima: Imprenta del Estado, 1904.

Memoria del Ministro de Guerra y Marina 1905. Lima: Imprenta del Estado, 1905.

Memoria del Ministro de Guerra y Marina 1906. Lima: Tipografía de El Perú de Ricardo Flores y Cía, 1906.

Memoria del Ministro de Guerra y Marina 1907. Lima: Imprenta del Estado, 1907.

Memoria del Ministro de Guerra y Marina 1908. Lima: Tipografía El Progreso Literario, 1908.

Memoria que el Ministro de Guerra y Marina presenta al Congreso Ordinario de 1893. Lima: Imprenta Liberal de F. Masías y Cía 1893.

Memoria que el Ministro de Guerra y Marina presenta al Congreso Ordinario de 1901. Lima: Imprenta Liberal, 1901.

Memoria que el Ministro de Estado en el despacho de Guerra y Marina presenta al Congreso. Lima: Tipografía de Aurelio Alfaro y Cía. 1861.

Memoria que presenta el Ministro en el despacho de Guerra y Marina al Congreso Nacional de 1862. Lima: Imprenta de la Época, 1862.

Memoria que presenta al Congreso Ordinario de 1888 el Ministro de Estado en el despacho de Guerra y Marina, Elías Mujica. Lima: Imprenta Torres Aguirre, 1888. 


\section{Bibliografía}

Aljovín, Cristóbal. "Elecciones y oficiales del ejército: Perú 1827-1896”.

Journal of Iberian and Latin American Research (2014): 50-65.

Borgoño Justiniano. Memoria que presenta al Sr. General Jefe de E. M.

General del Ejército. El Jefe de la Comisión Militar de los Departamentos de Lima, Ica, Junín y provincia constitucional del Callao. Año de 1902 (Lima: Imprenta La Industria, 1902), 11.

Camacho, Carlos. El reclutamiento, los soldados y la experiencia del cuartel: servicio militar obligatorio en Perú y Colombia (1919-1933). Revista de Indias Vol. LXXVIII No. 272 (2018): 263-287.

Caravaglia, Juan Carlos. Las fuerzas de guerra en la construcción del Estado: América Latina, siglo XIX. Rosario: Prohistoria, 2012.

Centeno, Miguel Ángel. Sangre y deuda. Ciudades, Estado y construcción de nación América Latina. Bogotá: Editorial Universidad Nacional de Colombia, 2014.

Fisher, John. El Perú borbónico 1750-1824. Lima: Instituto de Estudios Peruanos, 2000.

Fisher, John. Fidelismo, patriotismo e independencia. En La independencia del Perú ¿concedida, conseguida, concebida?, editado por Carlos Contreras y Luis Miguel Glave. Lima: Instituto de Estudios Peruanos, 2015.

Garavaglia, Juan Carlos et al. Las fuerzas de guerra en la construcción del Estado: América Latina, siglo XIX. Rosario: Prohistoria, 2012.

Hidalgo et al. Historia del Ejército en la República. Siglo XIX. Vol. 1. Lima: Comisión Permanente de la Historia del Ejército del Perú, 2005.

Marchena, Juan y Manuel Chust. Por la fuerza de las armas. Ejército e Independencias en Iberoamérica. Castellón: Universidad Jaume I, 2007.

McEvoy, Carmen. La Guerra Maldita. Domingo Nieto y su correspondencia (1834-1844). Vol. I. Lima: Ministerio de Cultura, 2015.

McNeill, William. La búsqueda del poder: tecnología, fuerzas armadas y sociedad desde el 1000 d.C. Madrid: Siglo XXI Editores, 1988.

Méndez, Cecilia. "Las paradojas del autoritarismo: ejército, campesinado y etnicidad en el Perú, siglos XIX al XX.” Íconos (2000): 29-30. 
Méndez, Cecilia. Las paradojas del autoritarismo: ejército, campesinado y etnicidad en el Perú, siglos XIX al XX. Íconos (2006): 17-34.

Mücke, Ulrich. Política y burguesía en el Perú. El Partido Civil antes de la Guerra con Chile. Lima: IFEA-IEP, 2015.

Ortiz Escamilla, Juan. Fuerzas militares en Iberoamérica, siglos XVIII y XIX. México: Colegio de México-Colegio de Michoacán-Universidad Veracruzana, 2005.

Pardo, Manuel. Mensaje como Presidente de la República al Congreso ordinario en el año 1876. En Manuel Pardo: Escritos Fundamentales, editado por Carmen McEvoy. Lima: Fondo del Congreso de la República, 2004.

Parker, Geoffrey. La revolución militar. Innovación militar y apogeo de Occidente 1500-1800. Madrid: Alianza Editorial, 2002.

Sánchez, Susy. Civiles vestidos de militares En Historias compartidas: economía, sociedad y poder, siglos XVI-XX, editado por Margarita Guerra, Cristina Mazzeo y Denisse Rouillón. Lima: Instituto Riva Agüero, 2007.

Sobrevilla, Natalia. Ciudadanos armados: las guardias nacionales en la construcción de la Nación en el Perú de mediados de siglo XIX. En Independencia y ciudadanía en Hispanoamérica (1750-1850), editado por Manuel Chust y Juan Marchena. Madrid: Iberoamericana-Vervuert, 2007, 178-179.

Tristán, Flora. Peregrinaciones de una paria. Lima: Centro de la mujer peruana Flora Tristán-UNMSM, 2005.

Velásquez, David. Ejército, política y sociedad en el Perú, 1821-1879. Trashumante. Revista Americana de Historia Social No. 12 (2018): 142164.

Velásquez, David. Indios, soldados sin patria. Líneas Generales Vol. II (2018): 56-72.

Velásquez, David. La reforma militar y el gobierno de Nicolás de Piérola. El Ejército moderno y la construcción del Estado peruano. (Tesis de Mg, Historia-UNMSM, 2013). <http://cybertesis.unmsm.edu.pe/ handle/cybertesis/3391>.

Velásquez, David. Una historia de los registros del estado civil en el siglo XX. RENIEC. Identidad digital. La identificación desde los registros parroquiales al DNI electrónico. Lima: RENIEC, 2015, 537-567. 
Velásquez, David. Una mirada de largo plazo: armas, política y guerra en el siglo XIX. En Tiempo de Guerra. Estado, nación y conflicto armado en el Perú, siglos XVII-XIX, editado por Carmen McEvoy y Alejandro Rabinovich. Lima: Instituto de Estudios Peruanos, 2018. 495-537.

Para citar este artículo: Velásquez Silva, David Víctor. "La reforma de la conscripción en el Perú en el tránsito del siglo XIX al XX. La aplicación de la Ley del Servicio Militar Obligatorio de 1898", Historia Caribe, Vol. XIV No. 35 (Julio-Diciembre 2019): 213-246. DOI: http://dx.doi. org/10.15648/hc.35.2019.8 